\title{
Health-related quality of life outcomes at 1 and 5 years after a residential retreat promoting lifestyle modification for people with multiple sclerosis
}

\author{
Emily J. Hadgkiss • George A. Jelinek • Tracey J. Weiland • \\ Greg Rumbold · Claire A. Mackinlay · Siegfried Gutbrod • \\ Ian Gawler
}

Received: 16 October 2011 / Accepted: 9 February 2012/Published online: 25 February 2012

(C) The Author(s) 2012. This article is published with open access at Springerlink.com

\begin{abstract}
There is a strong body of evidence that supports the use of non-drug therapies in the management of people with multiple sclerosis (MS). A 5-day residential retreat for people with MS in Victoria, Australia, promotes lifestyle modification within a patient-centred model of care. Analysis of the health-related quality of life (HRQOL) of the retreat participants was undertaken using the MSQOL54 , prior to attendance, 1 and 5 years after the retreat. 274 retreat participants $(71 \%)$ completed baseline questionnaires. Despite the usually progressive nature of MS, the cohort demonstrated clinically and statistically significant improvements in HRQOL. One year after attending the retreat, median improvements of $11.3 \%$ were observed in the overall quality of life domain $(p<0.001) ; 18.6 \%$ in the physical health composite $(p<0.001)$; and $11.8 \%$ in the mental health composite $(p<0.001)$. In the subset of 165 who had reached the 5-year time-point, there was a $19.5 \%$ median improvement in overall quality of life $(p<0.001)$; $17.8 \%$ in the physical health composite $(p<0.001)$ and $22.8 \%$ in the mental health composite $(p<0.001)$, compared to baseline. Attendance at a retreat promoting lifestyle modification for the integrated management of MS appears to have positive effects on short and medium-term
\end{abstract}

E. J. Hadgkiss · G. A. Jelinek ( $)$ · T. J. Weiland ·

C. A. Mackinlay

Emergency Practice Innovation Centre, St. Vincent's Hospital,

Fitzroy, P.O. Box 2900, Melbourne, VIC 3065, Australia

e-mail: george.jelinek@gmail.com

G. A. Jelinek - T. J. Weiland

Faculty of Medicine, Dentistry and Health Sciences,

University of Melbourne, Melbourne, Australia

G. A. Jelinek · G. Rumbold · S. Gutbrod · I. Gawler

The Gawler Foundation, Yarra Junction, VIC, Australia
HRQOL. Non-drug therapies should be considered as part of any comprehensive treatment plan for people with MS.

Keywords Quality of life - MSQOL-54 .

Multiple sclerosis · Well-being · Lifestyle

\section{Introduction}

Multiple sclerosis (MS) is the most common progressive neurological disorder affecting young adults [1]. Women are twice as likely as men to be affected with MS, with an estimated incidence rate of 3.6 per 100,000 [2], varying considerably with geographic region. MS is thought to be immune-mediated, however, despite decades of research, the aetiology and factors that trigger relapses and influence disease progression continue to be debated [3]. Disease activity and clinical course are unpredictable, usually resulting in a broad range of symptoms and functional limitations, with depression and fatigue the most common [4]. Many patients report feelings of hopelessness and uncertainty, particularly if they are not actively engaged in decision-making about their care [5]. Additionally, MS can have a major impact on families due to increased role responsibilities, social isolation, employment challenges and financial hardship.

Current treatment options for MS focus mainly on pharmaceutical intervention. First line immune-modulating drugs such as beta interferon and glatiramer acetate reduce relapse rates by around 30\%, show MRI evidence of reducing disease activity, and can help preserve cognition; however there remain concerns regarding the short- and long-term side effects of such drugs and whether they make a real difference to the progression of the illness [6-8]. Nonetheless, observational studies have suggested that the 
disease-modifying treatments may have increased the survival, with somewhat slower accumulation of disability, raising the possibility of a new natural history of the illness [9]. This may, however, to some extent reflect increased recognition of MS with better diagnostic techniques [9].

Comprehensive literature also exists examining the relationship between modifiable lifestyle and psychosocial factors and MS progression [10]. However, most clinicians adopt a drug-only approach to disease modification, despite calls for a more integrated approach [11].

Consumer demand for non-drug intervention is evident through the large proportion of people with MS using complementary and alternative medicines in addition to mainstream medical treatment [12]. Likewise, wellness programmes provide a supportive, informative environment well-suited to assist individuals in self-managing their diverse symptomatology. Despite this, there is limited literature evaluating the effectiveness of this type of approach to MS management. Two systematic reviews [13, 14] of wellness programmes discuss the importance of patient-centred, multidisciplinary approaches in the management of chronic illness. Both studies found that despite the reported benefit of wellness programmes, the existing literature is deficient and mainly consists of only short-term follow-up.

A live-in educational programme at The Gawler Foundation in Victoria, Australia, provided a unique opportunity to assess the impact of such modifiable lifestyle factors on MS outcomes. Due to the unpredictable nature of the illness, is it important to evaluate MS outcomes in the medium to long-term. To date, apart from our published findings of health-related quality of life (HRQOL) outcomes at one and two-and-a-half years after attending this programme [15], there have been no other studies examining the effect of a multimodal residential programme promoting lifestyle modification for people with MS. As we have continued to collect follow-up data from this cohort, we aimed to present results of analyses of the cohort at the 1 and 5 year marks post-retreat.

\section{Materials and methods}

\section{Programme}

Since April 2002, a 5-day live-in programme for people with MS has been operating two to three times a year at The Gawler Foundation in the Yarra Valley in Victoria, Australia. Funded by donations and course fees, this notfor-profit organisation is experienced with operating integrated wellness programmes for people living with chronic illness and can accommodate up to 36 people, including partners and carers of people with MS. The only other comparable programme is offered by the MS Society of Auckland and the North Shore in New Zealand, facilitated by one of the authors [16]. The MS programme has been designed in accordance with the available literature that supports the integrated management of MS with: a low-fat, plant-based diet; exercise; sunlight exposure; vitamin D and omega-3 supplementation; and meditation and stress reduction techniques (Box 1). The evidence supporting the programme interventions has been discussed elsewhere [10, 11, 15, 17-19]. In addition to provide evidence-based education about lifestyle modification, participants engage in daily meditation, group and individual counselling, gentle exercise, yoga and Qigong. The programme is taught in a dynamic, interactive way which allows the participants to share their experiences and ask questions. Beyond the programme, the facilitators encourage participants to develop the various modalities into an ongoing treatment regime with medical oversight by their usual healthcare providers.

Box 1 Retreat recommendations (adapted from Li et al. [15])

Diet and supplements

Plant-based wholefood diet plus fish; minimal saturated fat

Omega-3 fatty acid supplements: $20 \mathrm{~g}$ a day (flaxseed or fish oil)

Vitamin D

Sunlight 15 min daily 3-5 times a week

Vitamin D3 5,000 IU daily

Aim for vitamin D level around $150 \mathrm{nmol} / \mathrm{L}$

Meditation

30 min daily

Exercise

30 min 5 times a week

Medication

One of the disease-modifying drugs, beginning early in the illness if possible, if required

Steroids for any distressing acute relapse

Methods

Participants who enrolled in a MS retreat at The Gawler Foundation were invited to take part. In order to attend the retreat, participants must be over 18 years of age and speak English proficiently. Anyone who self-reported being diagnosed with MS by a neurologist was eligible for the study. Those providing consent completed a validated questionnaire, the Multiple Sclerosis Quality Of Life (MSQOL-54) [20], prior to attending the retreat, and again at 1-, 2.5- and 5-year time-points. The 2.5-year time-point was phased out in 2009 to reduce the burden of compliance. A funded research officer commenced oversight of 
the dataset in 2008. The research officer attempted to locate participants who had changed address and actively sought responses from participants. An online questionnaire was offered to participants for baseline and follow-up in addition to the existing paper-based version in February 2009. Only those who completed a baseline were invited to continue participation. In the early phase of the study clerical issues meant that some groups did not receive an invitation to participate at the 1-year time-point.

\section{Ethics}

A detailed explanation of the research was given to all participants at every time-point and formal, written consent was obtained. It was emphasised that a decision to decline participation would not affect their experience or interactions with staff at The Gawler Foundation. Approval to conduct this study was granted by the Human Research Ethics Committee of the University of Melbourne (HREC ID: 0723028.1). All survey data were subjected to confidentiality and patient codes were only re-identified for the purpose of contacting participants for follow-up.

\section{Evaluation tool}

Evaluation of the programme at the time-points was facilitated by patient self-report using the MSQOL-54, which has been adapted from the RAND 36-item health survey and has demonstrated sound psychometric properties [20]. Since the introduction of the MSQOL-54 in 1995, it has been widely used as an outcome measure and has been culturally and linguistically adapted for the purpose of international research [21-24]. In addition to the core health survey questions, the MSQOL-54 has been supplemented to include measures of health distress, sexual function, energy, pain and social function, thus giving rise to 14 scales. Table 1 shows the weighted sum of selected domains which determine physical and mental health composite scores. Like the individual scale scores, the composite scores range from 0 to 100 , with higher scores indicating a better health outcome.

\section{Statistical analysis}

As the data were not normally distributed (KolmogorovSmirnov statistic), the Friedman's test and Wilcoxon Signed Ranks test were used to make comparisons between baseline, 1- and 5-year time-points and the Mann-Whitney $U$ test to compare the cohort with those lost to follow-up. Medians were used as summary statistics. The evaluation of the 2.5-year surveys was published elsewhere [15] and as no new data were available for this time point, it was excluded from analysis. The time-points were assessed
Table 1 Weighted sum of MSQOL 54 domains

\begin{tabular}{lllll}
\hline \multicolumn{2}{l}{ Physical health composite } & & \multicolumn{2}{l}{ Mental health composite } \\
\cline { 1 - 1 } \cline { 5 - 6 } Domains & Weight & & Domains & Weight \\
\hline Physical function & 0.17 & & Health distress & 0.14 \\
Health perceptions & 0.17 & & Overall quality of life & 0.18 \\
Energy/fatigue & 0.12 & & Emotional well-being & 0.29 \\
Role limitations due to & 0.12 & & Role limitations due to & 0.24 \\
physical problems & & & emotional problems \\
Pain & 0.11 & & Cognitive function & 0.15 \\
Sexual function & 0.08 & & \\
Social function & 0.12 & & \\
Health distress & 0.11 & & \\
\hline
\end{tabular}

separately as few participants completed all three surveys. Prior to analysis of the data, the level of significance was defined as $p<0.05$. All statistical analyses were carried out with PASW 18.0 software.

\section{Results}

Participation rates

A total of 394 participants attended a retreat for MS at The Gawler Foundation between April 2002 and August 2010. Seven were excluded from the study as they were not formally diagnosed with MS or had another neurological condition. All 387 eligible participants completed the full 5-day programme. Of those eligible to participate, 274 (71\%) completed a baseline questionnaire, of whom 227 $(83 \%)$ were female. Due to the predominant representation of women in the cohort, gender comparisons were not made. The smaller subset of participants who completed 5 -year surveys is due to the limited number $(n=165)$ who had completed a baseline questionnaire and reached the 5-year time-point. A smaller number of people completed surveys at all three time-points $(n=47)$.

Participation rates vary between domains as they have been adjusted according to the scoring criteria set by Vickrey 1995 [20], which requires a minimum number of items to be completed to give rise to a domain score. Accordingly, there is variation in the response rates for individual domains at each time-point. Baseline overall quality of life was compared between those who only completed baseline and were subsequently lost to followup and those who completed baseline and at least one other time-point. There was no statistically significant difference in the physical health composite $(p=0.414)$ or mental health composite $(p=0.131)$ between these two groups when compared using the Mann-Whitney $U$ test. 
Domain rank comparison baseline, 1 and 5 years

The Friedman test was conducted to compare results for each domain at all three time-points and detected significant differences in 9 of 14 domain scores and both mental and physical health composites (Table 2). As only 47 participants had completed surveys at all time-points, separate post hoc tests were run to compare baseline to 1-year results and baseline to 5-year results, which represented a larger proportion of the cohort.

1-year time-point

Of the 270 participants sent invitations at the 1-year timepoint, surveys were completed by 196 participants, for a $73 \%$ response rate. At 1 year, 13 of 14 domains and both composite scores showed positive median changes, demonstrating improvements in HRQOL. The median changes were significantly different from zero in 11 of these 13 domains and both physical and mental health composite scores. No change in median score was observed in role limitations due to emotional problems, although the Wilcoxon Signed Ranks test detected a significant difference $(p=0.002)$. Improvements for physical health and sexual function were not statistically significant. The greatest change over time was seen in the domains: role limitations due to physical problems; change in health; and satisfaction with sexual function. They all demonstrated a 50\% (25 point) improvement 1 year after baseline. The smallest statistically significant improvement was observed for cognitive function, which increased by five points. At 1 year overall quality of life improved $11.3 \%(p<0.001)$, physical health composite $18.6 \%(p<0.001)$ and mental health composite $11.8 \%(p<0.001)$ (Table 3; Fig. 1).

5-year time-point

Similar changes were detected at the five year time-point (Table 4). Of those reaching the 5-year time-point $(n=165)$, surveys were completed by 96 participants, for a $58 \%$ response rate. Improvements were observed in 11 of the 14 MSQOL domains, of which nine were statistically significant. Three domains detected no change over time including change in health, sexual function and satisfaction with sexual function. The latter two domains were not statistically significant, nor were physical health or pain scale scores. Akin to 1 year, despite no median change over time, significant differences were still detected by the Wilcoxon Signed Ranks test for change in health $(p=0.009)$. The biggest improvements after 5 years were observed in role limitations due to physical problems with a 37.5 point increase ( $100 \%$ median difference; $p=0.001$ ), followed by a 17.5-point median improvement in health distress $(p<0.001)$. Both the mental health and physical health composites were statistically significant and improved over time with a percentage median difference of 22.8 and $17.8 \%$ respectively, over 5 years, with an overall improvement in quality of life of $19.5 \%(p<0.001)$ (Table 4 ; Fig. 1).

\section{Discussion}

Our study, the first of its kind, indicates a significant persistent improvement in short- and medium-term HRQOL
Table 2 Comparison of mean ranks at baseline, one year and five year time points

Differences assessed using Friedman test

$n$ Number of participants

\begin{tabular}{lllllrl}
\hline Domain scores and composite scores & $n$ & \multicolumn{3}{l}{ Mean rank } & Chi-square & $p$ value \\
\cline { 3 - 5 } & & & Baseline & 1 year & 5 year & \\
\hline Physical function & 47 & 1.89 & 2.13 & 1.98 & 1.653 & 0.438 \\
Role limitations-physical & 46 & 1.74 & 2.18 & 2.08 & 8.309 & 0.016 \\
Role limitations-emotional & 43 & 1.73 & 2.12 & 2.15 & 11.400 & 0.003 \\
Pain & 46 & 1.97 & 2.13 & 1.90 & 1.708 & 0.426 \\
Emotional well-being & 47 & 1.61 & 1.94 & 2.46 & 19.602 & 0.000 \\
Energy & 47 & 1.60 & 2.24 & 2.16 & 12.489 & 0.002 \\
Health perceptions & 46 & 1.55 & 2.08 & 2.37 & 17.815 & 0.000 \\
Social function & 43 & 1.77 & 2.01 & 2.22 & 5.729 & 0.057 \\
Cognitive function & 47 & 1.74 & 2.24 & 2.01 & 7.789 & 0.020 \\
Health distress & 45 & 1.44 & 2.23 & 2.32 & 23.346 & 0.000 \\
Sexual function & 42 & 2.11 & 2.05 & 1.85 & 1.942 & 0.379 \\
Overall quality of life & 47 & 1.51 & 2.18 & 2.31 & 20.808 & 0.000 \\
Change in health & 45 & 1.76 & 2.37 & 1.88 & 14.356 & 0.001 \\
Satisfaction with sexual function & 41 & 1.87 & 2.23 & 1.90 & 4.748 & 0.093 \\
Physical health composite & 37 & 1.57 & 2.30 & 2.14 & 10.865 & 0.004 \\
Mental health composite & 41 & 1.54 & 2.20 & 2.27 & 13.317 & 0.001 \\
\hline
\end{tabular}


Table 3 Comparison of domain and composite scores at baseline and 1-year time-points

\begin{tabular}{|c|c|c|c|c|c|c|c|}
\hline Domain & $n$ & $\begin{array}{l}\text { Baseline } \\
\text { Median (IQR) }\end{array}$ & 1 year & $\begin{array}{l}\text { Domain point } \\
\text { difference }\end{array}$ & $\begin{array}{l}\% \text { median } \\
\text { difference }\end{array}$ & $Z$ score & $p$ value \\
\hline Physical health & 190 & $75.0(40.0-90.0)$ & $80.0(45.0-95.0)$ & 5.0 & 6.7 & -1.401 & 0.161 \\
\hline Role limitations-physical & 194 & $50.0(0.0-100.0)$ & $75.00(0.00-100.00)$ & 25.0 & 50.0 & -3.791 & $<0.001$ \\
\hline Role limitations- emotional & 185 & $100.0(33.3-100.0)$ & $100.0(66.7-100.0)$ & 0.0 & 0.0 & -3.108 & 0.002 \\
\hline Pain & 190 & $85.8(70.0-100.0)$ & $93.3(76.7-100.0)$ & 7.5 & 8.7 & -3.044 & 0.002 \\
\hline Emotional well-being & 196 & $72.0(60.0-84.0)$ & $80.0(68.0-88.0)$ & 8.0 & 11.1 & -4.696 & $<0.001$ \\
\hline Energy & 196 & $48.0(32.0-67.0)$ & $60.0(40.0-72.0)$ & 12.0 & 25.0 & -4.658 & $<0.001$ \\
\hline Health perceptions & 191 & $60.0(45.0-75.0)$ & $70.0(55.0-85.0)$ & 10.0 & 16.7 & -5.658 & $<0.001$ \\
\hline Social function & 183 & $75.0(58.3-91.7)$ & $83.3(66.7-91.7)$ & 8.3 & 11.1 & -3.319 & 0.001 \\
\hline Cognitive function & 190 & $80.0(60.0-90.0)$ & $85.0(65.0-95.0)$ & 5.0 & 6.3 & -3.603 & $<0.001$ \\
\hline Health distress & 190 & $62.5(43.8-80.0)$ & $80.0(60.0-90.0)$ & 17.5 & 28.0 & -7.446 & $<0.001$ \\
\hline Sexual function & 166 & $79.2(58.4-91.7)$ & $83.4(58.3-100.0)$ & 4.2 & 5.3 & -0.590 & 0.555 \\
\hline Overall quality of life & 195 & $73.4(60.0-81.7)$ & $81.7(68.4-86.7)$ & 8.3 & 11.3 & -5.433 & $<0.001$ \\
\hline Change in health & 194 & $50.0(25.0-50.0)$ & $75.0(50.0-75.0)$ & 25.0 & 50.0 & -7.017 & $<0.001$ \\
\hline Satisfaction with sexual function & 168 & $50.0(25.0-75.0)$ & $75.0(50.0-100.0)$ & 25.0 & 50.0 & -2.130 & 0.033 \\
\hline Physical health composite & 149 & $63.7(48.6-77.8)$ & $75.50(56.4-84.9)$ & 11.8 & 18.6 & -5.408 & $<0.001$ \\
\hline Mental health composite & 178 & $72.9(51.9-85.1)$ & $81.5(68.7-90.3)$ & 8.6 & 11.8 & -5.697 & $<0.001$ \\
\hline
\end{tabular}

Differences analysed using Wilcoxon Signed Rank test

$n$ Number of participants, IQR interquartile range

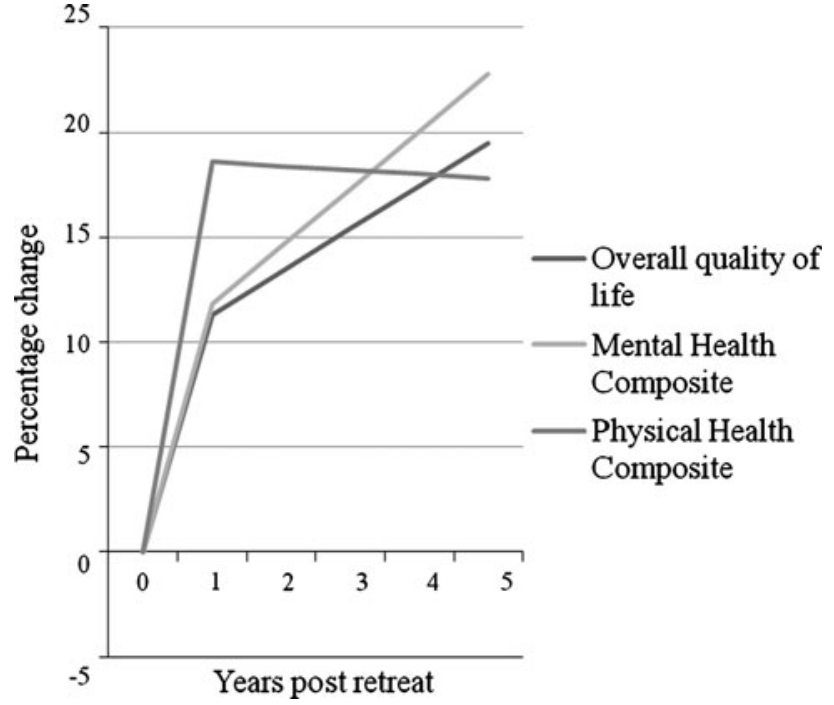

Fig. 1 Percentage change in median MSQOL-54 composite and overall quality of life scores at baseline, 1 and 5 years after a residential retreat. *All differences represent significant improvement $(p<0.001)$ from baseline

for people with MS after attending a live-in educational retreat. 1 and 5 years after attendance, most of the MSQOL-54 domains demonstrated significant improvements, with no domain detecting a decline in self-reported HRQOL. This applied to both mental and physical health composites, which continued to improve over the 5-year time frame. As MS is known to result in deteriorating quality of life and increasing disability over time, these results are remarkable.

MS can have a profound impact on a person's quality of life and in the absence of a cure, maintenance of function and quality of life are the focus of treatment. Clinical outcome measures of relapse rate and disability are insufficient alone to assess the impact of disease, thus a more broad measurement tool is required [25, 26]. HRQOL is a multifaceted concept that incorporates the symptom-related impact of disease as well as psychosocial aspects such as fatigue, emotional well-being or participation [27]. A quality of life tool can be used to assess health disparities within a population or the effectiveness of interventions. Self-reported data in MS cohorts have been found to be a reliable measure of patient outcomes [28, 29]. In our study, due to the varied level of participant disability, both hardcopy and online questionnaire formats were offered to ease facilitation of survey completion. The online format was found to be the preferred method of most participants.

The mental health composite scores demonstrated clinically and statistically significant improvements at both 1 and 5-year time points. This is important because prevalence rates of depression and anxiety are high in patients with MS and can affect the way a patient copes with the limitations of the disease [30]. Social isolation and a lack of social support can further exacerbate psychological decline, leading to poorer quality of life [30, 31]. "Invisible" symptoms of MS (depression, anxiety, fatigue and 
Table 4 Comparison of domain and composite scores at baseline and 5-year time-points

\begin{tabular}{|c|c|c|c|c|c|c|c|}
\hline Domain & $n$ & $\begin{array}{l}\text { Baseline } \\
\text { Median (IQR) }\end{array}$ & 5 year & $\begin{array}{l}\text { Domain point } \\
\text { difference }\end{array}$ & $\begin{array}{l}\% \text { median } \\
\text { difference }\end{array}$ & $Z$ score & $p$ value \\
\hline Physical health & 96 & $75.0(46.3-95.0)$ & $82.5(40.0-95.0)$ & 7.5 & 10.0 & -1.122 & 0.262 \\
\hline Role limitations-physical & 96 & $37.5(0.0-100.0)$ & $75.0(6.3-100.0)$ & 37.5 & 100.0 & -3.921 & $<0.001$ \\
\hline Role limitations-emotional & 92 & $83.3(0.0-100.0)$ & $100.0(66.7-100.0)$ & 16.7 & 20.0 & -3.967 & $<0.001$ \\
\hline Pain & 95 & $85.0(70.00-100.00)$ & $93.33(71.7-00.0)$ & 8.3 & 9.8 & -0.669 & 0.503 \\
\hline Emotional well-being & 96 & $72.0(56.0-84.0)$ & $80.0(68.0-88.0)$ & 8.0 & 11.1 & -4.328 & $<0.001$ \\
\hline Energy & 96 & $48.0(29.0-64.0)$ & $56.0(40.0-72.0)$ & 8.0 & 16.7 & -3.735 & $<0.001$ \\
\hline Health perceptions & 95 & $60.0(45.0-75.0)$ & $75.0(55.0-85.0)$ & 15.0 & 25.0 & -4.334 & $<0.001$ \\
\hline Social function & 90 & $75.0(58.3-91.7)$ & $83.3(66.7-100.0)$ & 8.3 & 11.1 & -2.875 & 0.004 \\
\hline Cognitive function & 96 & $80.0(56.3-90.0)$ & $85.0(65.0-95.0)$ & 5.0 & 6.3 & -2.023 & 0.043 \\
\hline Health distress & 94 & $62.5(35.0-80.0)$ & $80.0(63.8-95.0)$ & 17.5 & 28.0 & -6.100 & $<0.001$ \\
\hline Sexual function & 84 & $75.0(58.3-91.7)$ & $75.0(50.0-91.7)$ & 0.0 & 0.0 & -0.167 & 0.868 \\
\hline Overall QOL & 95 & $68.4(58.4-81.7)$ & $81.7(63.4-90.0)$ & 13.3 & 19.5 & -3.603 & $<0.001$ \\
\hline Change in health & 94 & $50.0(25.0-50.0)$ & $50.0(50.0-75.0)$ & 0.0 & 0.0 & -2.599 & 0.009 \\
\hline Satisfaction with sexual function & 87 & $50.0(25.0-75.0)$ & $50.0(25.0-75.0)$ & 0.0 & 0.0 & -0.417 & 0.667 \\
\hline Physical health composite & 78 & $64.5(47.4-78.4)$ & $75.9(56.8-87.7)$ & 11.4 & 17.8 & -3.887 & $<0.001$ \\
\hline Mental health composite & 89 & $67.4(50.2-85.1)$ & $82.8(72.1-90.1)$ & 15.4 & 22.8 & -4.924 & $<0.001$ \\
\hline
\end{tabular}

Differences analysed using Wilcoxon Signed Rank test

$n$ Number of participants, $I Q R$ interquartile range

pain) can be more difficult to assess clinically but are thought to have a greater impact on health distress [32]. More concerning, is evidence demonstrating the effect that poor psychological health can have on disease progression. A meta-analysis [33] of the relationship between stressful life events and MS exacerbations found a clinically meaningful effect size. This supports earlier work showing an increased risk of brain lesions 8 weeks after the occurrence of stress, with preoccupation and coping as moderators of this effect [34]. The stress reduction techniques and meditation taught at the retreats may assist participants in coping with high levels of stress and drive the considerable improvements in the mental health composite scores. Such interventions can easily be incorporated into a management plan for dealing with adjustment issues and stress and may also slow disease progression.

People with MS constitute a heterogeneous group with diverse needs and modes of adaptation in coping with the limitations of the illness [35]. In contrast with physicians, people with MS may view physical disability as less important than other quality of life dimensions such as emotional well-being and vitality [36]. The process of patient-centred care involves engaging individuals and encouraging them to share in the decision-making role to create a disease management plan that incorporates their physical, psychological and socio-cultural needs [37]. Shifting the paradigm of MS care to a patient-centred approach has the potential to improve patient outcomes and satisfaction with the provider's service [5]. It is thought that mastery, or the degree to which people feel they are in control of their illness, plays an important role in health status. Patients with higher levels of self-efficacy and empowerment report lower rates of depression [38] and are more likely to effectively self manage their illness through the appropriate utilisation of services and treatment adherence [39]. The facilitators have recognised tailoring patient-centred care and fostering empowerment as important approaches in the design and operation of our MS programme. This might help explain why patients report lower rates of health distress and improved emotional well-being 5 years after the retreat.

Despite improvements in the sexual health domains at the 1-year time-point, no change was observed at 5 years. Sexual dysfunction is common in MS with $40-85 \%$ of women and 50-90\% of men being adversely affected [40]. One study found a significant negative correlation between sexual dysfunction and nearly all MSQOL-54 domains [41]. It presents a significant burden for self-esteem and relationships but unfortunately, this problem is insufficiently addressed by both the person with MS and the physician who are often reluctant to discuss it [42]. Although there was no worsening of sexual function, perhaps the programme could be adapted to more openly discuss some of the potential solutions to this prevailing issue. Pain is also a difficult management issue, with no really effective pharmacological agents available, and no 
significant change in pain detected at the 5-year point following our programme.

The global improvements in health status observed over the 5-year period are considerably better than one would expect, given the usually progressive, degenerative nature of the illness. While it is difficult to make comparisons with other studies as few have observed patients for more than 2 years, in general, studies measuring HRQOL over time report a predominant decline in the health status of the participants [43-46]. One study [45], which measured MSQOL-54 over a 5-year period documented no change, or a worsening in 11 of the 14 health domains. This contrasts dramatically with our study. A wellness programme for women in the United States [47] saw some improvements in pain and mental health scales, however, the follow-up concluded only 8-months after the intervention.

\section{Limitations}

A longitudinal cohort study is the appropriate method to assess outcomes in MS, which is usually progressive and varies for individuals over time. The absence of a control group, and declining response rates over time, however, decrease the strength of the evidence. With more than half the participants returning 5-year follow-up data, and no domain worsening over that period, it is unlikely, however, that we are simply observing a benign MS group, who are thought to comprise only a small fraction of people with MS, and whose quality of life and function are documented to deteriorate over time [48].

It is difficult to know which aspects of the programme had the greatest impact on self-reported quality of life. The favourable results could be viewed as being related to the participants' altered perception of quality of life over time, as opposed to a tangible change, or that they simply learned to cope with the limitations of the disease. This is unlikely though, because most studies have shown deterioration in HRQOL over time using the MSQOL-54. Additionally, there may have been participation bias, although there is no clear reason why those not providing consent to participate would have had a different course than those participating. Similarly, the follow-up results may, in part, be attributed to responder bias. However, comparison of the baseline overall quality of life domain showed no significant difference between participants who only completed a baseline questionnaire and those who continued to contribute data at the 1 or 5 year time-points.

We do not currently know the degree to which participants adhered to each individual lifestyle intervention longterm. Future research on this cohort will include measures of programme adherence. Additionally, it is unknown to what degree pharmaceutical intervention had an impact on quality of life, both in terms of reduced relapse rates and worsening of HRQOL due to side effects. We can, however, anecdotally report that many of the participants were not taking immune-modulating therapies.

MS diagnosis was self-reported by participants. The few people reporting neurological disorders other than MS were permitted to take part in the programme but excluded from analysis. Additionally, it is unknown which type of MS the participants had been diagnosed with and whether they were representative of the average distribution in the general MS population.

\section{Conclusion}

This study adds to the evidence supporting the use of integrated non-drug therapies for people with MS. Lifestyle modification should form part of any comprehensive chronic disease management plan, and given that there are likely to be other health benefits associated with this approach, there is considerable merit in offering this to people with MS. In addition to the benefits patients should experience, there are also likely to be reduced healthcare costs and improved satisfaction with the health service. The promotion of lifestyle intervention is not in competition with the use of pharmacological therapies; both should be considered for their potential benefits and risks, with decisions tailored to the needs of the individual. Trials assessing the impact of lifestyle modification long-term are methodologically complex and there are fewer financial incentives to invest in such research. Regardless, this study adds to the evidence supporting the use of a range of lifestyle interventions for people with MS.

Acknowledgments We thank The Bloom Foundation for the financial support for this study, along with a generous donation from Annie and Jim Simpson. We are grateful to all the staff at The Gawler Foundation for their ongoing support of this programme, and all the participants who returned questionnaires.

Open Access This article is distributed under the terms of the Creative Commons Attribution License which permits any use, distribution, and reproduction in any medium, provided the original author(s) and the source are credited.

\section{References}

1. Murray TJ (2006) Diagnosis and treatment of multiple sclerosis. BMJ 332:525-527

2. Koutsouraki E, Costa V, Baloyannis S (2010) Epidemiology of multiple sclerosis in Europe: a review. Int Rev Psychiatry 22:2-13

3. Marrie RA (2004) Environmental risk factors in multiple sclerosis aetiology. Lancet Neurol 3:709-718

4. Ziemssen T (2009) Multiple sclerosis beyond EDSS: depression and fatigue. J Neurol Sci 277(Suppl 1):S37-S41 
5. Simmons RD (2010) Life issues in multiple sclerosis. Nat Rev Neurol 6:603-610

6. Clegg A, Bryant J (2001) Immunomodulatory drugs for multiple sclerosis: a systematic review of clinical and cost effectiveness. Expert Opinion on Pharmacother 2:623-639

7. Chaudhuri A, Behan PO (2005) Treatment of multiple sclerosis: beyond the NICE guidelines. QJM 98:373-378

8. Bryant J, Clegg A, Milne R (2001) Systematic review of immunomodulatory drugs for the treatment of people with multiple sclerosis: Is there good quality evidence on effectiveness and cost? J Neurol Neurosurg Psychiatry 70:574-579

9. Tremlett H, Zhao Y, Ricckmann P, Hutchinson M (2010) New perspectives in the natural history of multiple sclerosis. Neurol 74:2004-2015

10. D'Hooghe MB, Nagels G, Bissay V, De Keyser J (2010) Modifiable factors influencing relapses and disability in multiple sclerosis. Mult Scler 16:773-785

11. Jelinek GA, Hassed CS (2009) Managing multiple sclerosis in primary care: are we forgetting something? Qual Prim Care 17:55-61

12. Leong EM, Semple SJ, Angley M, Siebert W, Petkov J, McKinnon RA (2009) Complementary and alternative medicines and dietary interventions in multiple sclerosis: what is being used in South Australia and why? Complem Ther Med 17:216-223

13. Stuifbergen AK, Morris M, Jung JH, Pierini D, Morgan S (2010) Benefits of wellness interventions for persons with chronic and disabling conditions: a review of the evidence. Disabil Health J 3:133-145

14. Watt D, Verma S, Flynn L (1998) Wellness programs: a review of the evidence. CMAJ 158:224-230

15. Li MP, Jelinek GA, Weiland TJ, Mackinlay CA, Dye S, Gawler I (2010) Effect of a residential retreat promoting lifestyle modifications on health-related quality of life in people with multiple sclerosis. Qual Prim Care 18:379-389

16. Jelinek GA (2010) Overcoming multiple sclerosis mana retreat. http://bit.ly/oOVOUl. Accessed October 132011

17. Jelinek GA (2005) Taking control of multiple sclerosis: natural and medical therapies to prevent its progression. Fleetbooks, Lancaster

18. Jelinek GA (2010) Overcoming multiple sclerosis: an evidencebased guide to recovery. Allen and Unwin, Sydney

19. Jelinek GA (2011) The Overcoming Multiple Sclerosis Recovery Program. http://www.overcomingmultiplesclerosis.org/. Accessed September 152011

20. Vickrey BG, Hays RD, Harooni R, Myers LW, Ellison GW (1995) A health-related quality of life measure for multiple sclerosis. Qual Life Res 4:187-206

21. Idiman E, Uzunel F, Ozakbas S, Yozbatiran N, Oguz M, Callioglu B, Gokce N, Bahar Z (2006) Cross-cultural adaptation and validation of multiple sclerosis quality of life questionnaire (MSQOL54) in a Turkish multiple sclerosis sample. J Neurol Sci 240:77-80

22. Heiskanen S, Merilainen P, Pietila A-M (2007) Health-related quality of life-testing the reliability of the MSQOL-54 instrument among MS patients. Scandinav J Caring Sci 21:199-206

23. Pekmezovic T, Kisic Tepavcevic D, Kostic J, Drulovic J (2007) Validation and cross-cultural adaptation of the disease-specific questionnaire MSQOL-54 in Serbian multiple sclerosis patients sample. Qual Life Res 16:1383-1387

24. Solari A, Filippini G, Mendozzi L, Ghezzi A, Cifani S, Barbieri E, Baldini S, Salmaggi A, Mantia LL, Farinotti M, Caputo D, Mosconi P (1999) Validation of Italian multiple sclerosis quality of life 54 questionnaire. J Neurol Neurosurg Psychiatry 67:158-162

25. Miller D, Rudick RA, Hutchinson M (2010) Patient-centered outcomes: translating clinical efficacy into benefits on healthrelated quality of life. Neurol 74(Suppl 3):S24-S35
26. Nortvedt MW, Riise T (2003) The use of quality of life measures in multiple sclerosis research. Mult Scler 9:63-72

27. Opara JA, Jaracz K, Brola W (2010) Quality of life in multiple sclerosis. J Med Life 3:352-358

28. Gold SM, Schulz H, Monch A, Schulz KH, Heesen C (2003) Cognitive impairment in multiple sclerosis does not affect reliability and validity of self-report health measures. Mult Scler 9:404-410

29. Ingram G, Colley E, Ben-Shlomo Y, Cossburn M, Hirst C, Pickersgill T, Robertson N (2010) Validity of patient-derived disability and clinical data in multiple sclerosis. Mult Scler $16: 472-479$

30. Jose Sa M (2008) Psychological aspects of multiple sclerosis. Clin Neurol Neurosurg 110:868-877

31. Dennison L, Moss-Morris R, Chalder T (2009) A review of psychological correlates of adjustment in patients with multiple sclerosis. Clin Psychol Rev 29:141-153

32. White CP, White MB, Russell CS (2008) Invisible and visible symptoms of multiple sclerosis: which are more predictive of health distress? J Neurosci Nurs 40:85-95

33. Mohr DC, Hart SL, Julian L, Cox D, Pelletier D (2004) Association between stressful life events and exacerbation in multiple sclerosis: a meta-analysis. BMJ 328:731

34. Mohr DC, Goodkin DE, Nelson S, Cox D, Weiner M (2002) Moderating effects of coping on the relationship between stress and the development of new brain lesions in multiple sclerosis. Psychosom Med 64:803-809

35. Flynn S (2002) Multiple sclerosis: the Treetops model of residential care. Br J Nurs 11(9):635-642

36. Rothwell PM, McDowell Z, Wong CK, Dorman PJ (1997) Doctors and patients don't agree: cross sectional study of patients' and doctors' perceptions and assessments of disability in multiple sclerosis. BMJ 314:1580-1583

37. Pelzang R (2010) Time to learn: understanding patient-centred care. Br J Nurs 19:912-917

38. Wallin MT (2010) Integrated multiple sclerosis care: new approaches and paradigm shifts. J Rehab Res Dev 47:ix-xiv

39. Mosen DM, Schmittdiel J, Hibbard J, Sobel D, Remmers C, Bellows J (2007) Is patient activation associated with outcomes of care for adults with chronic conditions? J Ambul Care Manage 30:21-29

40. Kessler TM, Fowler CJ, Panicker JN (2009) Sexual dysfunction in multiple sclerosis. Expert Rev Neurother 9:341-350

41. Tepavcevic DK, Kostic J, Basuroski ID, Stojsavljevic N, Pekmezovic T, Drulovic J (2008) The impact of sexual dysfunction on the quality of life measured by MSQoL-54 in patients with multiple sclerosis. Mult Scler 14:1131-1136

42. Fletcher SG, Castro-Borrero W, Remington G, Treadaway K, Lemack GE, Frohman EM (2009) Sexual dysfunction in patients with multiple sclerosis: a multidisciplinary approach to evaluation and management. Nat Clin Pract Urol 6:96-107

43. Miller DM, Rudick RA, Baier M, Cutter G, Doughtery DS, Weinstock-Guttman B, Mass MK, Fisher E, Simonian N (2003) Factors that predict health-related quality of life in patients with relapsing-remitting multiple sclerosis. Mult Scler 9:1-5

44. Hopman WM, Coo H, Pavlov A, Day AG, Edgar CM, McBride EV, Brunet DG (2009) Multiple sclerosis: change in healthrelated quality of life over two years. Can J Neurol Sci 36:554-561

45. Solari A, Ferrari G, Radice D (2006) A longitudinal survey of self-assessed health trends in a community cohort of people with multiple sclerosis and their significant others. J Neurol Sci 243:13-20

46. Wynia K, Wijlen AV, Middel B, Reijneveld S, Meilof J (2011) Change in disability profile and quality of life in multiple sclerosis patients: a five-year longitudinal study using the Multiple 
Sclerosis Impact Profile (MSIP). Mult Scler. doi:10.1177/1352 458511423935

47. Stuifbergen AK, Becker H, Blozis S, Timmerman G, Kullberg V (2003) A randomized clinical trial of a wellness intervention for women with multiple sclerosis. Arch Phys Med Rehabil 84:467476

48. Glad S, Nyland H, Myhr KM (2006) Benign multiple sclerosis. Acta Neurol Scand Suppl 183:55-57 